\title{
Contribuições do PIBID para a formação de licenciandos de Ciências Humanas
}

PIBID contributions to the training of Human Sciences licensors

Evandro Ricardo Guindani Ângela Maria Hartmann Yáscara Michele Neves Koga

Resumo: O Programa Institucional de Bolsas de Iniciação à Docência (PIBID) fomentado pela Coordenação de Aperfeiçoamento de Pessoal de Nivel Superior (CAPES), tem proporcionado a licenciandos uma possibilidade de aprendizagem docente muito peculiar e significativa antes mesmo de iniciarem seus estágios curriculares obrigatórios. Este texto apresenta uma breve análise da formação de professores no Brasil, posteriormente um histórico da política educacional do PIBID. Em seguida, contextualiza o PIBID dentro da Universidade Federal do Pampa e, por fim, apresenta uma pesquisa sobre a contribuição do Programa para a aprendizagem docente de acadêmicos bolsistas de iniciação à docência vinculados ao Curso de Ciências Humanas - Licenciatura. Os resultados apontam que o PIBID assumiu grande importância no processo de formação desses licenciandos, pois contribuiu para que eles construíssem sua identidade docente e compreendessem as peculiaridades da sala de aula.

Palavras-chave: PIBID; Formação Docente; Ciências Humanas; UNIPAMPA.

Abstract: The Institutional Program for Teaching Initiation Scholarships (PIBID) promoted by the Coordination for the Improvement of Higher Education Personnel (CAPES), has provided undergraduates with a very peculiar and meaningful possibility of teaching learning even before starting their mandatory curricular internships. This text presents a brief analysis of teacher training in Brazil, later a history of the educational policy of PIBID. Then, it contextualizes the PIBID within the Federal University of Pampa and, finally, presents a research on the contribution of the Program to the teaching learning of scholarship scholarship students linked to the Humanities Course - Licenciatura. The results show that PIBID has assumed great importance in the training process of these graduates, as it has contributed to them building their teaching identity and understanding the peculiarities of the classroom.

Keywords: PIBID; Teacher Education; Human Sciences; UNIPAMPA.

\section{Introdução}

Até 0 início do século $X X I$, as licenciaturas se estruturavam curricularmente por meio de dois blocos de "disciplinas", aquelas de formação específica e as conhecidas como didáticas ou pedagógicas. Era um currículo dividido e fragmentado. Além disso, os licenciandos apenas entravam em 
contato prático com a docência ao final do curso, durante o estágio supervisionado e obrigatório. Contudo, desde o final da década de 1990, as orientações curriculares para formação de professores vem apontando a necessidade de aliar teoria e prática desde os primeiros semestres dos cursos de licenciatura.

O artigo 65 da Lei de Diretrizes e Bases da Educação de 1996 (BRASIL, 1996) estabelece a obrigatoriedade de 300h de Prática de Ensino nos cursos de licenciatura. Posterior a esta legislação, outros pareceres e resoluções apontam a importância da prática estar aliada à teoria no processo de formação de professores, tais como o Parecer CNE/CP 009/2001 (BRASIL, 2001); Parecer CNE/CP 28/2001 (BRASIL, 2001b), Parecer CNE/CES 15/2005 (BRASIL, 2005), Resolução CNE/CP de 2002 (BRASIL, 2002) e a Resolução CNE/CP de 2015 (BRASIL, 2015), que estabelece que os cursos de licenciatura deverão ter em seu currículo 400h de Prática como Componente Curricular (PCC), o que foi mantido na mais recente Resolução CNE/CP de 2019, que define as Diretrizes Curriculares Nacionais para a formação inicial em nível superior (cursos de licenciatura, cursos de formação pedagógica para graduados e cursos de segunda licenciatura) e para a formação continuada (BRASIL, 2019).

O objetivo da inserção de PCC no currículo das licenciaturas é contribuir para que não haja mais esta dicotomia entre teoria e prática, bem como buscar acabar com certa inferiorização da dimensão prática em relação à formação teórica. Pereira (2011) afirma que esta dicotomia é histórica, remonta aos filósofos gregos clássicos que consideravam o "saber fazer" como inferior ao "filosofar". Para o autor, a prática docente possui uma estrutura epistemológica, constituindo-se em uma dimensão do conhecimento.

Para Schulman (apud PEREIRA, 2011) o saber docente se divide em: conhecimento sobre a matéria ensinada, conhecimento didático da matéria e conhecimento curricular. Sendo assim, a prática docente não é uma cópia da teoria. Para Pereira (2011), a prática docente é o momento que se busca construir algo a partir da teoria, que permeará essa prática. Como por exemplo, em Filosofia podemos sugerir aos alunos construir a maquete de uma cidade 
que esteja fundamentada na ética kantiana. Para fazer esta prática pedagógica, ele precisará dominar profundamente o conceito de ética em Kant. Para o autor, a PCC pode transcender a sala de aula, estendendo-se para o conjunto da rede do ambiente escolar, que abarca a família, a comunidade, as secretarias e coordenadorias de educação e, até mesmo, os sindicatos.

É dentro desta concepção de aliar teoria e prática que o Programa Institucional de Bolsa de Iniciação à Docência (PIBID) está inserido, fomentado pelo Ministério da Educação através da Coordenação de Aperfeiçoamento de Pessoal de Nivel Superior (CAPES). O Programa objetiva conciliar a formação teórica da educação superior com a realidade escolar. É uma política educacional que objetiva estimular o licenciando a vivenciar experiências na escola, contribuindo para a construção do seu saber docente, enquanto ele cursa a primeira metade do curso de licenciatura.

O subprojeto Ciências Humanas - objeto deste estudo - contava, em 2019, com 16 bolsistas, de um total de 266 bolsistas da Universidade Federal do Pampa (UNIPAMPA), atuando em duas escolas de Educação Básica, da cidade de São Borja, Rio Grande do Sul. Analisa-se neste texto a contribuição do PIBID na formação para a docência desses bolsistas. A pesquisa, de natureza qualitativa, foi realizada a partir de relatos extraídos dos portfólios, que registram as atividades desenvolvidas nas duas escolas, bem como de depoimento específico, solicitado pelos coordenadores do subprojeto, sobre o saber docente aprendido durante sua imersão nas escolas como bolsistas de iniciação à docência.

Neste artigo, apresentamos, inicialmente, uma breve análise da formação de professores no Brasil seguido de um histórico da política educacional sobre o PIBID. Em seguida contextualizamos o PIBID dentro da Unipampa e por fim apresentamos a contribuição do PIBID para a aprendizagem docente de acadêmicos bolsistas de iniciação à docência vinculados ao Curso de Ciências Humanas - Licenciatura. 


\section{A formação de professores para a Educação Básica no Brasil}

Como o PIBID está inserido dentro de uma política de formação de professores, cabe fazermos uma breve análise dessa política no Brasil. Não é objetivo deste texto fazer uma exposição linear sobre a formação de professores no Brasil, mas sim apresentar algumas reflexões a partir de estudos de pesquisadores do tema.

Marin (2010) destaca que desde a década de 1970, com ampliação na de 1980, a área de formação de professores tem sido objeto de atenção na formulação de ações políticas nos âmbitos federal, estaduais e municipais. Com relação à década de 1970, a autora destaca que houve uma maior exigência no domínio de conhecimentos gerais por adolescentes ingressantes em cursos de formação de professores. A autora destaca que, entre 1970 e 1980, também houve na legislação uma preocupação com os agentes técnicos e gestores que atuavam nas escolas. O grande problema, segundo ela, foi que esta formação passou a se dar dentro do próprio curso de Pedagogia. Contudo, ao entrarmos na década de 1990:

[...] o número e os tipos de ações se ampliaram muito na educação provocando profusão de leis, decretos, portarias e decorrências regulamentadoras da vida das escolas e das redes de ensino básico e superior com implicação direta, ou indireta, sobre a formação inicial e continuada de professores e sobre o desempenho de suas funções (MARIN, 2010, p. 151).

Uma das conquistas da década de 1990, segundo Marin (2010) foi a elaboração da Lei de Diretrizes e Bases da Educação, a LDB/1996 (BRASIL, 1996), que passou a exigir a formação de nível superior para o exercício da atividade docente. Segundo a autora, houve muitos atropelos no cumprimento dessa exigência, sobretudo por causa de uma onda de ações políticas voltadas à formação de professores a distância. Outro acerto na LDB/1996 foi estabelecer a obrigatoriedade de planos escolares do trabalho educativo, com destaque para a necessidade de participação dos professores neste processo.

Segundo Borges e outros (2011), em 1999, o Conselho Nacional de Educação publicou a Resolução $1 / 99$, que prevê, em seu artigo $1^{\circ}$, a nova proposta de estrutura formativa contida na LDB e, nos arts. $2^{\circ}$ e $3^{\circ}$, propôs um 
caráter orgânico para o funcionamento e flexibilidade de organização e denominação dos cursos de licenciatura. A Resolução trouxe também, em seu art. $4^{\circ} \S 1^{\circ} \mathrm{e}$ incisos, a preocupação com a qualidade do corpo docente para os institutos superiores de educação. Estabeleceu, também, exigências maiores com relação à formação dos formadores, estabelecendo uma porcentagem de docentes com qualificação em nível de mestrado, doutorado, dedicação exclusiva e comprovada experiência na Educação Básica. Por outro lado, não houve uma política de formação continuada, que sustentasse essas mudanças na legislação.

Ao analisar o perfil dos cursos de formação de professores a partir da década de 1990, Marin (2010) apresenta alguns estudos que detectam algumas falhas na formação pedagógica do professor, apontando, por exemplo, ausência de questões voltadas à prática profissional bem como de temáticas que abordassem as especificidades do ambiente onde se dá o ensino: a escola. Libâneo e Pimenta (1999), por sua vez, defendiam a necessidade de uma educação superior que contemplasse questões relacionadas à prática pedagógica.

Desde o ingresso dos alunos no curso, é preciso integrar os conteúdos das disciplinas em situações da prática que coloquem problemas aos futuros professores e lhes possibilitem experimentar soluções. Isso significa ter a prática, ao longo do curso, como referente direto para contrastar seus estudos e formar seus próprios conhecimentos e convicções a respeito. Ou seja, os alunos precisam conhecer o mais cedo possível os sujeitos e as situações com que irão trabalhar. Significa tomar a prática profissional como instância permanente e sistemática na aprendizagem do futuro professor e como referência para a organização curricular (LIBÂNEO e PIMENTA, 1999).

Marin (2010) apresenta a importância do que é dito por Gatti e Barreto (2009), ao afirmarem que nos cursos de formação de professores há um certo desprezo à formação pedagógica e maior centralidade na formação específica. Libaneo e Pimenta (1999) possuem uma reflexão nesta linha, apontando a necessidade de uma valorização identitária do professor de caráter epistemológico e profissional. Em outras palavras, para os autores, não é qualquer um que pode ser professor. Assim como esses autores, 
compreendemos que a profissão docente possui uma especificidade imersa num campo do conhecimento e uma área profissional específicos.

Libâneo e Pimenta (1999) apontam que, historicamente, institutos e departamentos de áreas específicas conceituadas pela ciência, ignoravam a produção de conhecimento sobre educação e ensino produzidos pelas faculdades de educação. Nesse sentido, observamos que mesmo em uma universidade com uma história mais recente, como a UNIPAMPA, com pouco mais de dez anos desde sua criação em 2008, o campo de produção de conhecimento sobre educação é menosprezado, inclusive por muitos licenciados.

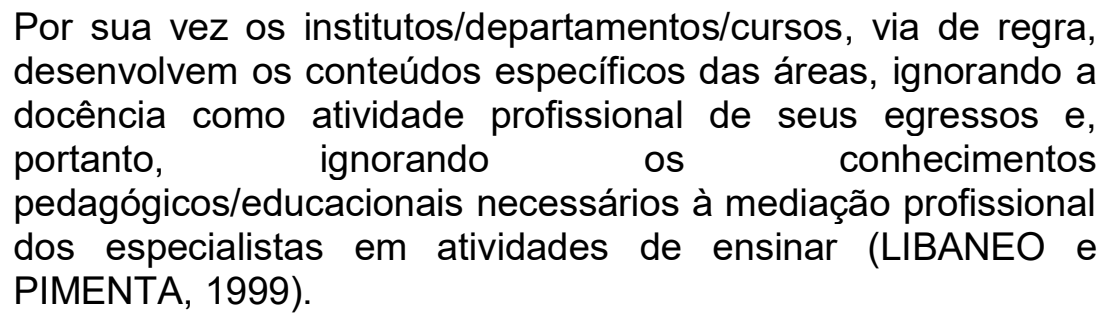

Prosseguindo nesta direção da relevância da formação pedagógica, Marin (2010) em sua análise do Relatório da Unesco dos anos de 2004 e 2007, destaca que boa parte dos professores brasileiros tem dificuldade de lidar com o problema da indisciplina em sala de aula, apresentando dificuldade em compreender e aceitar as características sociais dos alunos. Para Marin (2010), os acertos e desacertos no campo da formação de professores contribui para manter um cenário ambiguo de tensões e divergências, resultando em professores despreparados para exercer a docência.

Segundo Borges e outros (2011), a partir de 2002, quando foram promulgadas as Diretrizes Curriculares Nacionais para a Formação de Professores (DCN), é que foram feitas as primeiras adaptações nos currículos de formação docente. Posteriormente, foram promulgadas também as diretrizes curriculares para cada curso de licenciatura, aprovadas pelo Conselho Nacional de Educação. Os autores apontam que essas DCNs tiveram uma maior preocupação no desenvolvimento de competências pessoais, sociais e profissionais dos professores. A orientação das Diretrizes foram direcionadas para os professores que atuariam em diferentes níveis da 
Educação Básica. Os autores destacam que as Diretrizes recomendavam uma aprendizagem orientada pelo princípio da ação e reflexão, com foco na resolução de situações-problema. Uma das questões tambem apontada nessas Diretrizes é que a prática estivesse presente desde o inicio dos cursos.

Borges e outros (2011) apontam que uma Política Nacional para a Formação de Profissionais do Magistério da Educação Básica foi instituída pelo Decreto presidencial $n^{\circ} 6.755 / 2009$, dispondo sobre a atuação da Coordenação de Aperfeiçoamento de Pessoal de Nível Superior (CAPES) para o fomento a programas de formação inicial e continuada. Os autores ressaltam alguns pontos positivos deste decreto como a orientação para criação nos estados de Fóruns Permanentes de Apoio à Formação Docente. Outro destaque é que o Decreto propôs ações formativas, no sentido de prever a articulação entre as instituições de ensino superior e as redes de ensino da Educação Básica. É neste contexto que o Programa Institucional de Bolsa de Iniciação à Docência (PIBID) é criado, como uma das estratégias de aproximação dos cursos de licenciatura com as escolas de Educação Básica.

Cabe destacar também a aprovação pelo Conselho Nacional de Educação da Resolução 02, de 01 de julho de 2015, que define as Diretrizes Curriculares Nacionais para a formação inicial em nível superior (cursos de licenciatura, cursos de formação pedagógica para graduados e cursos de segunda licenciatura) e para a formação continuada. (BRASIL, 2015). Essa Resolução reforça a questão da presença da prática no currículo das licenciaturas desde o inicio do curso.

As políticas de valorização docente constituem outro elemento fortemente vinculado à questão da formação de professores e que aponta para um determinado perfil docente. Um estudo de Koga (2013) contribui para compreender como as políticas de valorização docente no Brasil estão fundamentadas na meritocracia. A autora discorre sobre a relação entre demandas do campo econômico para o campo educacional com foco nas políticas de formação e valorização docente. Por isso, consideramos importante destacar que muitas políticas educacionais de valorização docente 
possuem como pano de fundo uma lógica da culpabilização e responsabilização docente pelo sucesso ou fracasso do aluno.

\section{PIBID: História da política educacional}

O PIBID, de acordo com a Coordenadoria de Aperfeiçoamento de Pessoal de Nível Superior (CAPES), é uma ação da Política Nacional de Formação de Professores do Ministério da Educação (MEC) que busca proporcionar aos discentes na primeira metade do curso de licenciatura uma aproximação prática com o cotidiano das escolas públicas de Educação Básica e com o contexto em que elas estão inseridas. Essa ação da política educacional tem contribuído com o processo de formação de alunos das licenciaturas em todo o país, o que é evidenciado em artigos publicados em periódicos e trabalhos apresentados em eventos regionais e nacionais da área do encino e da educação.

O Programa concede bolsas para acadêmicos de Licenciatura e para professores das escolas de Educação Básica, onde os acadêmicos atuam. Além disso, o PIBID concede bolsas para professores das Instituições de Ensino Superior (IES) vinculados aos Cursos de Licenciatura que aderem ao Programa. De acordo com a CAPES, ao apromover a iniciação do licenciando no ambiente escolar ainda na primeira metade do curso, o Programa visa estimular, desde o início da formação, a observação e a reflexão sobre a prática profissional no cotidiano das escolas públicas de Educação Básica. A inserção dos licenciandos nas escolas é acompanhada por um professor da escola e por um docente das instituições de educação superior participantes do Programa.

De acordo com o Decreto 6.316 de 2007 (BRASIL, 2007), que aprova o Estatuto e o Quadro Demonstrativo dos Cargos em Comissão e das Funções de Confiança da Coordenação de Aperfeiçoamento de Pessoal de Nível Superior (CAPES), uma das finalidades da CAPES é fomentar programas de formação inicial e continuada de profissionais do magistério para a Educação Básica com vistas à construção de um sistema nacional de formação de professores. Cabe salientar que esta orientação já estava nos Decretos 6.316, 
de 2007, e 7.692, de 2012, os quais foram revogados por este decreto de 2017 . Em 9 de junho de 2009, é instituída pelo Ministério da Educação a Portaria $n^{\circ}$ 09 (BRASIL, 2009), a qual cria o Plano Nacional de Formação de Formação dos Professores de Educação Básica sob responsabilidade da CAPES. Esta Portaria determina que as IES públicas terão bolsas de iniciação à docência (ID) do PIBID. Na esteira de atribuições em relação à Educação Básica, foi emitida - pela CAPES - em 09 de abril de 2010, a Portaria de $n^{\circ} 72$ (BRASIL, 2010a) que dá nova redação à Portaria que dispõe sobre o PIBID. Nesta referida Portaria são definidos os objetivos do PIBID, a saber:

I) Incentivar a formação de professores para a Educação Básica, apoiando os estudantes que optam pela carreira docente; valorizar o magistério, contribuindo para a elevação da qualidade da escola pública; II) elevar a qualidade das ações acadêmicas voltadas à formação inicial de professores nos cursos de licenciatura das instituições de educação superior; III) inserir os licenciandos no cotidiano de escolas da rede pública de educação, promovendo a integração entre educação superior e Educação Básica; IV) proporcionar aos futuros professores participação em experiências metodológicas, tecnológicas e práticas docentes de caráter inovador e interdisciplinar e que busquem a superação de problemas identificados no processo de ensino-aprendizagem, levando em consideração o desempenho da escola em avaliações nacionais, como Provinha Brasil, Prova Brasil, SAEB, ENEM, entre outras; V) incentivar escolas públicas de Educação Básica, tornando-as protagonistas nos processos formativos dos estudantes das licenciaturas, mobilizando seus professores como co-formadores dos futuros docentes (BRASIL, 2010a).

Cabe salientar que esta referida Portaria foi baseada na Lei 11.502, de 11 de julho de 2007, do Governo de Luis Inácio Lula da Silva, que define mudanças nas competências da CAPES e, dentre outras atribuições, autoriza a concessão de bolsas de estudo e de pesquisa a participantes de programas de formação inicial e continuada de professores para a Educação Básica.

A Portaria $n^{\circ} 72 / 2009$ representa um grande avanço em termos de políticas educacionais para a formação de professores, aumentando a responsabilidade das IES no que tange às especificidades do universo da Educação Básica. É uma política que preza pela melhoria da qualidade na Educação Básica bem como pela melhoria na formação de novos professores. 
No ano de 2010, o então Presidente da República lança o Decreto 7.219, de 24 de junho de 2010 (BRASIL, 2010), o qual define as funções de cada bolsista dentro do PIBID, os objetivos do PIBID, o perfil das escolas participantes do Programa e dá outras determinações acerca do funcionamento do Programa dentro das IES. A Portaria da CAPES n 72/, de 09 de julho de 2010, determina novas orientações para o PIBID. No ano de 2018, a CAPES emite duas Portarias (Portaria $n^{\circ}$ 45, de 12 de março de 2018, e a Portaria $n^{\circ} 175$, de 07 de agosto de 2018) onde são feitas novas alterações na proposta do PIBID e também no Programa Residência Pedagógica.

No ano de 2019, ocorre um corte de bolsas por parte da CAPES, impedindo que os projetos institucionais concedessem cotas de bolsas de licenciandos afastados do PIBID a novos acadêmicos. Ou seja, caso algum bolsista, por algum motivo, fosse desligado do Programa, não havia mais possibilidade de incluir um substituto, prejudicando assim o andamento das atividades na escola, impossibilitando também que outro acadêmico pudesse se beneficiar de uma bolsa. Estes cortes no PIBID, que já vinham acontecendo desde 2016, não aconteceram somente no PIBID, conforme apontavam alguns portais de notícia do país em 2019:

A Coordenação de Aperfeiçoamento de Pessoal do Nível Superior (CAPES) anunciou nesta segunda-feira (2) o corte de 5.613 bolsas de mestrado, doutorado e pós-doutorado no Brasil a partir deste mês. É o terceiro comunicado do tipo neste ano. Ao todo, a CAPES vai deixar de oferecer cerca de 11 mil bolsas e não serão aceitos novos pesquisadores neste ano. A crise no financiamento das pesquisas afeta também o Conselho Nacional de Desenvolvimento Científico e Tecnológico (CNPq), ligado ao Ministério da Ciência. O CNPq também suspendeu a concessão de novas bolsas e os atuais bolsistas ainda correm risco de não receber a partir de setembro (CAPES CORTA 5.613 BOLSAS, 2019).

O que percebemos neste contexto de corte orçamentário é que as políticas que vinham buscando evoluir na melhoria do processo de formação de professores sofrem desvalorização, provocando uma precarização dos Programas PIBID e Residência Pedagógica. 


\section{O PIBID na Universidade Federal do Pampa}

A Unipampa é uma universidade multicampi, com campi em dez municípios da metade sul do Estado do Rio Grande do Sul: Bagé, Alegrete, Caçapava do Sul, Dom Pedrito, Uruguaiana, Itaqui, São Borja, Santana do Livramento, São Gabriel e Jaguarão. A Unipampa, em 2019, contava com mais de 11 mil alunos matriculados em 74 cursos de graduação, 35 de pósgraduação lato-sensu e 25 na modalidade stricto-sensu.

Numa análise comparativa entre municípios da região fronteiriça do Estado com municípios da região serrana, Guindani et al. (2017) destaca que a região onde se encontra a Unipampa apresenta baixos indicadores sociais e educacionais. Investigando a relação entre a realidade socioeconômica e o rendimento escolar dos alunos, a pesquisa comparou dois grupos de municípios. O primeiro grupo é composto por municípios localizados na região fronteiriça do Estado do Rio Grande do Sul, pertencentes a $35^{\mathrm{a}}$ e $10^{\mathrm{a}} \mathrm{CRE}$ (Coordenadoria Regional de Educação) e o segundo, composto por municípios localizados na região central e serrana do Estado mais próximos à capital, pertencentes à $4^{\mathrm{a}} \mathrm{CRE}$ (Coordenadoria Regional de Educação).

A partir da análise comparativa entre as duas regiões (fronteira e serra/centro), são possíveis vários apontamentos. O primeiro deles refere-se aos IDEB: a média dos municípios da fronteira alcança o índice de 3,79, enquanto na região central e serrana essa média sobe para 4,42. Com relação ao crescimento anual da população, dez dos doze municípios da fronteira apresentam um decrescimento populacional, enquanto, dentre os quatorze municípios da região serrana/central, apenas três apontam um decrescimento. Com relação ao IDH, na região da fronteira, apenas dois municípios possuem um índice que ultrapassa a casa dos 0,7 . Já na região serrana/central, apenas três estão na casa dos 0,7 , enquanto os outro onze estão acima de 0,8 . Com relação ao percentual de indigência e pobreza, na região da fronteira, onze de doze municípios possuem mais de $9 \%$ de pobres e indigentes dentre sua população, já na região serrana e central, apenas um município (dentre os catorze) possui mais de $9 \%$ de pobres e indigentes. 
Constata-se que a Unipampa se instala numa região com muitas demandas, o que justifica a relevância de bolsas de estudo para seus alunos. A bolsa de iniciação à docência proporcionada pelo PIBID contribui de forma efetiva no combate à evasão. O perfil dos alunos, principalmente de licenciatura, caracteriza-se, na sua grande maioria, pela situação de vulnerabilidade social.

A Unipampa aderiu ao PIBID no ano de 2009 e desde então participou de todos os editais da CAPES/PIBID. De acordo com Relatório de Atividades encaminhado à CAPES (UNIPAMPA, 2011), em 2011 foram contemplados 8 cursos de licenciatura e 90 bolsistas de iniciação à docência (ID). Em 2012 (UNIPAMPA, 2012), o número de cursos de licenciatura participantes subiu para 11, com 165 bolsistas ID. Em 2013 (UNIPAMPA, 2013) o número de bolsistas ID e de escolas permaneceu o mesmo. Em 2014 (UNIPAMPA, 2014), o número de cursos de licenciatura participantes do PIBID subiu para 16 e o número de bolsistas ID para 365. Em 2015 (UNIPAMPA, 2015), o número de escolas permanece o mesmo mas o número de bolsistas ID sobe para 430 . Em 2016, o número de cursos continua o mesmo, mas o número de bolsistas ID sobe para 435 (UNIPAMPA, 2016). Em 2017, segue com o mesmo número de cursos, porém o número de bolsistas ID cai para 428 .

De acordo com o Relatório de Atividades (UNIPAMPA, 2017), a falta de recursos de custeio impossibilitou a realização de muitas atividades em 2017, apesar de se ter conseguido manter praticamente o mesmo número de cotas de bolsa de iniciação à docência.

De acordo com Campelo e Cruz (2019) em 2017, o PIBID corria o risco de ser extinto, o que gerou grande mobilização pela sua continuidade em várias universidades. As autoras ressaltam que houve propostas de mudanças no seu formato, uma redução de $14,8 \%$ no número de bolsistas de 67 mil para 58 mil e o fomento caiu de 251 milhões para 220 milhões de reais. De acordo com as autoras, em 2017, o Ministro da Educação anunciou que o Programa seria reformulado e passaria a investir na Residência Pedagógica. No mês seguinte, proclamou-se que o Programa não acabaria, mas entraria em um "hiato" até meados de 2018, não estando claro o que isso significaria. Em 
fevereiro de 2018, circulou por e-mail e em redes sociais um anúncio do seu encerramento, não oficializado por nenhuma autoridade. A partir daí, foi iniciada uma série de batalhas (inclusive judiciais) buscando a prorrogação do último edital em vigência (2013). Conseguiu-se a manutenção do Programa, mas o novo edital de 2018 , da CAPES, alterou o tempo de duração dos projetos institucionais PIBID de 48 para 18 meses.

No ano de 2018, por meio do Edital da CAPES/MEC n. 07/2018 (BRASIL, 2018), a Unipampa submete novamente uma proposta do PIBID contemplada com 322 cotas de bolsas ID de um total de 3.494 cotas de bolsa destinadas a IES do Rio Grande do Sul. O projeto institucional contemplou quatro subprojetos, sendo um deles multidisciplinar com 9 (nove) núcleos de iniciação à docência, todos contemplados com 24 a 30 cotas de bolsas ID, três cotas de bolsa de supervisão para professores da Educação Básica e uma cota de coordenador de área para professor da instituição de Educação Superior.

É interessante observar que de 2016 - auge do número de bolsistas para outubro de 2019, o número de cotas mensais de bolsas de ID diminuiu em 169, o que faz uma grande diferença considerando a realidade sócio econômica da região onde se localiza a Unipampa. Além dessa grande queda na quantidade de boslas, houve outro agravante para a redução drástica do número de cotas a partir de julho de 2019, pois a CAPES não permitiu a substituição dos bolsistas desligados do projeto institucional. Com isso, desde outubro de 2019 a janeiro de 2020, o PIBID/Unipampa manteve apenas 266 bolsistas ID, deixando de conceder bolsas a 56 acadêmicos de licenciatura.

\section{Contribuições do PIBID para a aprendizagem docente dos licenciandos}

Apresentamos, a seguir, os resultados da pesquisa com o objetivo de identificar as contribuições do PIBID para a aprendizagem docente de acadêmicos bolsistas de iniciação à docência vinculados ao Curso de Ciências Humanas - Licenciatura. O referido curso iniciou suas atividades no campus São Borja no ano de 2013. O curso caracteriza-se por uma proposta de formação interdisciplinar dentro de quatro campos de conhecimento: Sociologia, Filosofia, Geografia e História. O Curso aderiu ao PIBID no ano de 
2014, com 30 bolsistas de iniciação à docência distribuídos em três escolas da cidade. Ao final do ano de 2019, o subprojeto Ciências Humanas, devido ao número de cotas reduzidas pela CAPES no Edital 07/2018, contava com 16 bolsistas de iniciação à docência.

A faixa etária dos bolsistas estava entre 20 e 25 anos. Quando ingressaram no subprojeto, em 2018, onze estavam cursando o segundo e cinco cursavam o quarto semestre. Os bolsistas formavam dois grupos de oito, distribuídos em duas escolas de Educação Básica da cidade. Cada grupo de bolsistas possuía um professor supervisor, que contribuía no planejamento das atividades, realizado sob a coordenação de docentes do Curso de Ciências Humanas, e supervisionava a atuação deles nas escolas. As duas escolas estão localizadas em bairros periféricos da cidade com estudantes provindos, em sua maioria, de famílias de baixa renda.

As atividades nas escolas eram planejadas a partir de temáticas já definidas no Projeto Institucional submetido ao Edital da CAPES, porém adaptadas à realidade da escola. Inicialmente, os bolsistas fizeram uma pesquisa socio antropológica, uma espécie de diagnóstico das turmas, buscando identificar principalmente o perfil socioeconomico e cultural dos alunos. A partir desse diagnóstico foram priorizadas determinadas ações.

Após um ano de atividade no PIBID (agosto de 2018 a agosto de 2019), os Coordenadores de Área solicitaram aos dezesseis bolsistas que produzissem reflexões sobre a contribuição do PIBID para sua formação docente. Estas reflexões se traduziram em manuscritos na forma de portfólios, artigos e relatos.

Os relatos dos bolsistas foram analisados de forma qualitativa e categorizados em cinco categorias usando como critério a semelhança do conteúdo dos depoimentos: (I) prática docente; (II) identidade docente; (III) conhecimento do contexto escolar; (IV) aprendizagem afetiva; e (V) conhecimento do perfil do aluno. 


\section{(I) Prática docente}

A prática em sala de aula, mesmo não sendo ainda de regência, fez ver aos bolsistas, a importância de ter um plano "b" para as aulas, no caso de acontecer algum imprevisto, bem como de usar estratégias didáticas que fizessem os alunos sentirem-se seguros para expressar ideias e argumentos.

Aprendi a desenvolver atividades sempre pensando em ter um plano $B$, pois os imprevistos sempre estão presentes, tendo como exemplo uma atividade na qual os alunos deveriam dialogar sobre o racismo apresentado em músicas, e eles não estavam tão participativos, e nós os dividimos em grupos e a participação foi bem maior, pois eles se sentiam mais seguros em grupos para argumentar. (Bolsista Deise).

Além de reconhecer a importância de elaborar atividades que estimulem a curiosidade dos alunos, os bolsistas realçaram a importância de tê-las bem preparadas previamente. Uma das bolsistas destacou que,

[...] acompanhar a rotina escolar e aplicar as oficinas faz com que eu perceba que a preparação para uma aula é extremamente importante, e que existem outros fatores além do conteúdo que envolvem as relações entre professores e alunos. (Bolsista Jana).

Trabalhar com alunos pouco receptivos a mudanças na rotina escolar e à integração com os colegas foi uma experiência bem importante para os bolsistas. Para Paulo, as atividades do PIBID o fizeram compreender a importância de:

[...] incentivar o aluno (a) a sair da facilidade da cópia e fazê-lo buscar, inovar e ser criativo. Dessa forma, eles também serão estimulados ao trabalho em equipe, buscando serem solidários sempre.

A inserção dos bolsistas de iniciação à docência no cotidiano escolar para que adquiram experiência de criação e participação em práticas docentes, aprendendo a como superar dificuldades ao se deparar com situações deafiadoras, é um dos objetivos do PIBID:

Inserir os licenciandos no cotidiano de escolas da rede pública de educação, proporcionando-lhes oportunidades de criação e participação em experiências metodológicas, tecnológicas e práticas docentes de caráter inovador e interdisciplinar que 
busquem a superação de problemas identificados no processo de ensino-aprendizagem (BRASIL, 2020).

Também fica evidente nos relatos dos bolsistas que tanto a teoria aprendida na universidade como a prática experienciada na escola são importantes no processo de formação de professores. De acordo com um dos bolsistas,

[...] a principal questão foi o primeiro contato dos graduandos com a escola, na prática, porém pode-se dizer que ocorreu a união entre teoria (vista na universidade) e a aplicação (só sendo capaz através de políticas públicas como o PIBID) dos conteúdos vistos da universidade. (Bolsista Jonas).

As declarações dos bolsistas quanto à relação teoria e prática vem ao encontro de um dos objetivos do PIBID preconizados pela CAPES: "Elevar a qualidade da formação inicial de professores nos cursos de licenciatura, promovendo a integração entre educação superior e Educação Básica" (BRASIL, 2020). Ainda em relação à teoria e prática, a CAPES prevê que o PIBID contribua "para a articulação entre teoria e prática necessárias à formação dos docentes, elevando a qualidade das ações acadêmicas nos cursos de licenciatura" (Ibidem)

\section{(II) Identidade docente}

É interessante observar que o bolsista de iniciação a docência está num meio termo entre ser docente e aprendiz, mas neste meio termo ele consegue captar o que é específico da profissão docente. Um dos atributos da profissão, ressaltado pelos bolsistas, foi o da responsabilidade docente. $O$ relato a seguir destaca a compreensão deles sobre o compromisso docente na realização das atividades pedagógicas:

[...] a responsabilidade do que é ser um professor e a importância de carregar no papel docente a incumbência de fazer com que o aluno assimile o conteúdo [e] também tenha capacidade crítica transformando isso em algo significativo na sua formação pessoal. (Bolsista Gilberto).

Esse relato é relevante para compreender a complexidade da ação docente, evitando julgamentos e principalmente a culpabilização e a 
responsabilização docente pelo sucesso ou fracasso escolar. Koga (2013) aborda a relação entre a lógica da meritocracia e a culpabilização dos individuos pelos fracassos e sucessos na sociedade. A autora afirma que em alguns documentos da área da educação o professor é visto como o principal agente responsável pelas mudanças da educação, o que acaba sendo uma sobrecarga nos ombros do docente. Portanto o PIBID faz com que os licenciandos compreendam que a realidade da escola é muito mais complexa do que o resultado direto entre a ação do professor e o rendimento do aluno.

O PIBID tem proporcionado conhecer a prática docente no chão da escola, como afirma a bolsista Arlete: "É interessante observar que nesse quase um ano de PIBID adquiri uma perspectiva diferenciada, e por que não dizer mais realista, sobre a carreira que escolhi para o meu futuro." O PIBID tambem contribuiu para os bolsistas perceberem as especificidades da prática docente em cada realidade, em cada escola, e perceber assim a dimensão política da prática docente:

Reconheço que o PIBID foi um divisor de águas na minha
formação, as situações que surgiram durante esse percurso
não só abriram meus olhos com relação ao sistema público de
ensino, que muitas vezes é desvalorizado e deixado de lado,
(...) mas também percebi como os professores que trabalham
em escolas periféricas se dedicam, até mesmo de forma
desgastante, para driblar os empecilhos e passar para os
alunos o máximo que podem. (Bolsista Arlete).

A consciência que os bolsistas construiram em relação ao trabalho docente tambem vem ao encontro de um dos objetivos do PIBID que é "contribuir para a valorização do magistério" (BRASIL, 2020).

\section{(III) Conhecimento do contexto escolar}

Com relação ao conhecimento sobre o contexto escolar, os bolsistas ressaltaram que puderam conhecer o Projeto Político Pedagógico (PPP) das escolas, conseguiram compreender o currículo, as especificidades do ambiente escolar como os horários de aula e a rotina do funcionamento das atividades. Puderam ainda, conforme o relato do bolsista Jonas, observar: "o quanto é corrido a rotina de um professor. Nesse curto período, deu para conhecermos a 
comunidade escolar e como que as coisas funcionam." O bolsista Vitório ressaltou que o PIBID "foi muito importante para nos depararmos com a realidade das escolas e articularmos melhor nossas atividades, conhecendo o perfil dos alunos".

Com relação ao PPP, Vitório relata que: "a educação, segundo o PPP, tem um viés de fazer os alunos partirem do ambiente ao seu redor, o que lhes é familiar", destacando que "ao questionar alguns alunos e professores percebe-se que algumas atividades e estudos realmente buscam integrar 0 conhecido pelo aluno, a cidade e afins".

\section{(IV) Aprendizagem afetiva}

Quanto à aprendizagem afetiva, os bolsistas ressaltaram que uma das aprendizagens que o PIBID proporcionou foi a da importância da afetividade entre professor e aluno. Para a bolsista Janaína, as atividades no PIBID propiciaram a percepção da "importância em construir um ambiente afetivo com os alunos para mostrar que a sala de aula não é um lugar onde apenas se 'escuta e executa', mas sim de trocas de experiências". Assim como entre professor e aluno, há também a importância de uma boa relação afetiva entre colegas, o que remete à uma boa relação entre colegas docentes.

Com relação ao trabalho em equipe com os colegas, a bolsista Tânia ressaltou: "a interação com meus colegas pibidianos contribuiu para uma melhor desenvoltura em trabalhos em grupo". Uma das bolsistas destaca que:

A convivência no grupo de pibidianos também gera um aproveitamento em relação, ao curso e a docência em si, até porque futuramente estaremos dentro de um grupo de professores de uma determinada escola, seria uma espécie de "simulação" de um futuro próximo. (Bolsista Fabiana).

O bolsista Roberto destacou a afetividade dos alunos com relação ao acolhimento e como esse acolhimento os motiva a seguirem persistentes na carreira docente:

Ser pibidiano é algo diferente pois você é visto diferente e sempre bem recebido pelos alunos, com sorrisos e olhares" [e] embora exista a desvalorização da docência é o que anima e 
dá energias para continuar lutando pra dar o melhor de si nas atividades.

Como o PIBID proporciona a bolsa de iniciação à docencia nos primeiros semestres do Curso, podemos considerar que o mesmo torna-se um importante fator na diminuição da evasão, que geralmente ocorre nos primeiros semestres. Pelo que foi possível perceber, o PIBID, para os bolsistas, foi fundamental no estímulo à entrada na carreira docente.

\section{(V) Conhecimento do perfil do aluno}

No que se refere à importância do perfil do aluno, os bolsistas ressaltaram a relevância da aplicação do questionário socioantropológico, por meio do qual eles puderam identificar o perfil socioeconômico, familiar e cultural dos alunos. Esta atividade contribuiu para compreender a importância da individualidade de cada aluno, da heterogeneidade de perfis existentes em uma sala de aula. Fabiana destaca a importância de saber, na profissão docente, quem é o aluno:

Com o PIBID eu aprendi a valorizar e a reconhecer o que significa trabalhar a partir do que o teu aluno é, e o que ele traz para a sala de aula, pois apesar de ouvir isso em sala na Universidade, não era algo perceptível pra mim. (Bolsista Fabiana).

Em síntese, é possível perceber que o PIBID contribui de fato para que o licenciando, já no início do curso, aprenda sobre o que é a docência, conforme apontou uma das bolsistas:

O projeto também proporciona uma experiência que permite que ao fim da formação acadêmica, ao ir trabalhar em uma escola, já se tenha conhecimento de como as coisas funcionam na atividade docente, tornando assim um ambiente não tão novo e desafiador. (Bolsista Jana).

O PIBID também proporcionou vivências que, de outra forma, seriam possíveis somente no estágio curricular obrigatório dos cursos de licenciatura, conforme aponta Jones: "Experiências que apenas apareceriam no estágio e que os pibidianos já puderam colocar em prática tão logo nos primeiros semestres de licenciatura". O contato com a realidade de trabalho no início do 
processo de formação é uma das grandes possibilidades ofertadas pelo PIBID. Ao oportunizar que os bolsistas se deparem com os desafios da futura profissão, o PIBID contribui para que eles façam uma auto avaliação do acerto da sua escolha profissional.

\section{Considerações finais}

A escrita deste texto nos possibilitou compreender a importância da relação entre teoria e prática no processo de formação de professores nas nossas licenciaturas. É preciso admitir a necessidade de romper com um paradigma dualista que comportava em duas etapas distintas a formação específica e a formação pedagógica. O PIBID é uma política educacional que contribui para demonstrar a relevância da indissociabilidade entre formação específica e formação pedagógica na formação docente, desfazendo a dissociação entre formação técnico-científica e formação docente que existia até alguns anos atrás. Ao separar as disciplinas do campo do conhecimento específicos das disciplinas chamadas pedagógicas, essa concepção de formação dicotômica concebia como elementos separados o campo científico e o campo do ensino. Ao romper com o paradigma dicotômico, o PIBID busca promover no licenciando uma compreensão mais aprofundada da especificidade do campo do ensino.

O campo do ensino unifica de forma indissociável o campo de conhecimento específico (por exemplo a História ou a Física) com a dimensão pedagógica. Para se ensinar um conteúdo é preciso antes de mais nada dominá-lo, porém o simples dominio do conteudo nao garante ao sujeito que ele consiga ensiná-lo. O ensino é um campo muito mais complexo do que o domínio do conteúdo especifico de um campo de conhecimento.

No ensino entram inúmeros fatores tais como, a escola, o perfil do aluno, o contexto socio cultural e economico do aluno, as concepções de aprendizagem, as formas de aprendizagem de cada aluno, as especificidades da profissão docente dentro de todo o contexto das políticas educacionais de um país, de um estado ou de um município. Não é raro encontrarmos docentes que são ótimos palestrantes, ótimos oradores dentro de seu domínio do campo 
do conhecimento porém não promovem o ensino aos seus alunos. Para promover 0 ensino ele precisa adentrar neste campo pedagógico extremamente complexo que é a dinâmica do ensino-aprendizagem. O PIBID, de acordo com o relato dos bolsistas, proporciona ao futuro professor a percepção da necessidade dessa apropriação do campo pedagógico. Ao estudar um conteúdo específico como a teoria da relatividade ou a teoria do conhecimento de Platão o bolsista do PIBID já estará se preocupando em como trabalhar este conteúdo com seu aluno da Educação Básica. Ele já se despertou para essa necessidade e aprenderá por meio do PIBID, que para ser um bom professor precisará mergulhar e compreender a indissociabilidade entre campo do conhecimento científico e a dimensão pedagógica.

Os resultados da pesquisa apontam que o PIBID vem proporcionando aos bolsistas relevantes experiências e vivências de aprendizagem docente, demonstrando a importância da continuidade desta política educacional, deviso à sua grande contribuição no processo de formação de professores. É desejável que esta política amplie-se para que possa contemplar mais acadêmicos de licenciatura, uma vez que é comum nos processos seletivos para o PIBID ter vários suplentes à espera de uma vaga.

\section{Agradecimento}

Agradecemos à Capes pelo financiamento das bolsas que proporcionaram o desenvolvimento das atividades no Pibid.

\section{Referências}

BORGES, M. C.; AQUINO, O. F; PUENTES, R. V. Formação de Professores no Brasil: História, Políticas e Perspectivas. Revista HISTEDBR On-line, Campinas, n.42, p.94-112, jun. 2011. Disponível em: https://periodicos.sbu.unicamp.br/ojs/index.php/histedbr/article/view/8639868/7 431. Acesso em: 01abr. 2020

BRASIL. Ministério da Educação. Conselho Nacional de Educação. Resolução $\mathrm{n}^{\circ}$ 2, de $\mathbf{1}^{\circ}$ de Julho de 2015. Disponível em: http://portal.mec.gov.br/docman/agosto-2017-pdf/70431-res-cne-cp-00203072015-pdf/file. Acesso em: 02 abr. 2020 
BRASIL. Ministério da Educação. Conselho Nacional de Educação. Resolução $\mathrm{n}^{\circ}$ 2, de 20 de dezembro de 2019. Disponível em: http://portal.mec.gov.br/conselho-nacional-de-educacao/calendario-dereunioes/30000-uncategorised/77781-resolucoes-cp-2019. Acesso em: 10 ago. 2020.

BRASIL. Presidencia Da República. Casa Civil. Lei de Diretrizes e Bases da Educação. Lei Número 9.394 de $20 \mathrm{dez}$ 1996. Disponível em: <http://www.planalto.gov.br/ccivil 03/leis/19394.htm> Acesso em 28 out. 2019.

BRASIL. Ministério da Educação. Conselho Nacional de Educação. Parecer CNE/CP 009 de 2001. Disponivel em: <http://portal.mec.gov.br/cne/arquivos/pdf/009.pdf> Acesso em: 25 out. 2019.

BRASIL. Ministério da Educação. Conselho nacional de educação. Parecer CNE/CP 282 de 2001.2 Disponível em: $<$ http://portal.mec.gov.br/cne/arquivos/pdf/028.pdf> Acesso em: 25 out. 2019.

BRASIL. Ministério da Educação. Conselho Nacional de Educação. Resolução CNE/CP núm. 02 de 2002. Disponível em: $<$ http://portal.mec.gov.br/cne/arquivos/pdf/028.pdf> Acesso em: 25 out. 2019.

BRASIL. Ministério da Educação. Conselho Nacional de Educação. Parecer CNE/CES 15 de 2005.2 Disponível em: <http://portal.mec.gov.br/cne/arquivos/pdf/pces0015_05.pdf> Acesso em: 25 out. 2019.

BRASIL. Ministério da Educação. Portaria 09 de 30 de Junho de 2009. Disponível em: http://portal.mec.gov.br/dmdocuments/port normt 09 300609.pdf > Acesso em: 16 out. 2019.

BRASIL. Ministério da Educação. Capes. Portaria 72 de 9 de abril de 2010. Disponível em: https://capes.gov.br/images/stories/download/legislacao/Portaria72_Pibid_0904 10.pdf> Acesso em: 16 out. 2019.

BRASIL. Diário Oficial da União. Decreto 7.219 de 24 de junho de 2010. Disponível em:

https://CAPES.gov.br/images/stories/download/legislacao/Decreto7219 PIBID 240610.pdf>. Acesso em: 16 out. 2019.

BRASIL. Ministério da Educação. Conselho Nacional de Educação. Resolução CNE/CP núm. 02 de 2015. Disponível em: $<$ http://portal.mec.gov.br/docman/agosto-2017-pdf/70431-res-cne-cp-00203072015-pdf/file> Acesso em: 25 out. 2019.

BRASIL. Presidência da República. Secretaria Geral. Subchefia de Assuntos Jurídicos. Decreto 8.977 de 30 de janeiro de 2017. Disponível em: < http://www.planalto.gov.br/ccivil 03/ Ato2015-

2018/2017/Decreto/D8977.htm\#art6> Acesso em: 16 out. 2019. 
BRASIL. Ministério da Educação. Capes. Chamada pública para apresentação de propostas: Edital $\mathrm{N}^{0} 7$ de 2018. Disponível em: < https://CAPES.gov.br/images/stories/download/editais/01032018-Edital-7-2018PIBID.pdf> Acesso em: 17 out. 2019.

BRASIL. Ministério da Educação. Capes. Objetivos do Programa (PIBID). 2020. Disponível em: https://www.CAPES.gov.br/educacaobasica/CAPESPIBID/PIBID. Acesso em: 27 mar. 2020

CAMPELO, T.; CRUZ, G.. O Edital CAPES n.07/2018 e a reconfiguração do PIBID: Sentidos de docência em disputa. Revista Práxis Educacional, Vitória da Conquista - Bahia - Brasil, v. 15, n.33, p. 69-90, jul./set. 2019. Disponível em: < http://periodicos2.uesb.br/index.php/praxis/issue/view/344> Acesso em: 25 out. 2019.

CAPES corta 5.613 bolsas a partir deste mês e prevê economia de r\$544 milhões em 4 anos. Portal G1 - Educação. 02/9/2019. Disponível em: $<$ https://g1.globo.com/educacao/noticia/2019/09/02/CAPES-deixa-de-oferecer5613-bolsas-a-partir-deste-mes-e-preve-economia-de-r-544-milhoes-em-4anos.ghtml> Acesso em: 17 out. 2019.

GATTI, B.; BARRETTO, E. S. S. (Coord.). Professores do Brasil: impasses e desafios. Brasília: UNESCO, 2009.

GUINDANI, E. R; GUINDANI, Y.; NASCIMENTO, S.. Desigualdades no Estado do Rio Grande do Sul: análise de indicadores sociais e educacionais. Rev. Educação e Fronteiras. v. 7, n. 20 (2017). Disponível em: <http://ojs.ufgd.edu.br/index.php/educacao/article/view/7455> Acesso em 19 out 2019.

KOGA, Y. Meritocracia e Docência: um objeto multifacetado. Tese de Doutorado. Programa de Pós-graduação em Educação: História, Política, Sociedade. PUC/SP. São Paulo-SP. 2013

LIBANEO, J. C.; PIMENTA, S. G. Formação de profissionais da educação: visão crítica e perspectiva de mudança. Educ. Soc., Campinas, v. 20, n. 68, p. 239-277, Dez. 1999. Disponível em: <http://www.scielo.br/scielo.php?script=sci_arttext\&pid=S010173301999000300013\&lng=en\&nrm=iso>. Acesso em: 30 mar. 2020.

MARIN, A. O Trabalho Docente: Uma "Caixapreta" Para os Professores. In: DALBEN, A; DINIZ, J; LEAL, L; SANTOS, L (Orgs). Convergências e Tensões no Campo da formação e do trabalho docente. Coleção Didática e Prática de Ensino. XV Endipe - Encontro Nacional de Didática e Prática De Ensino, Convergências e Tensões no Campo da Formação e do Trabalho Docente: Políticas e Práticas Educacionais. Belo Horizonte: Autêntica, 2010

PEREIRA, J. A prática como componente curricular na formação de professores. Educação. Santa Maria. Vol 36, n.2, p.203-218, maio/agosto. 2011 
UNIPAMPA. Pró-Reitoria de Graduação. Relatório Anual de Atividades do PIBID - 2012. Disponível em: <https://sites.unipampa.edu.br/PIBID/relatoriosde-atividades-PIBIDunipampa/> Acesso em: 20 out. 2019.

UNIPAMPA. Pró-Reitoria de Graduação. Relatório Anual de Atividades do PIBID - 2013. Disponível em: <https://sites.unipampa.edu.br/PIBID/relatoriosde-atividades-PIBIDunipampa/> Acesso em: 20 out. 2019.

UNIPAMPA. Pró-Reitoria de Graduação. Relatório Anual de Atividades do PIBID - 2014. Disponível em: <https://sites.unipampa.edu.br/PIBID/relatoriosde-atividades-PIBIDunipampa/> Acesso em: 20 out. 2019.

UNIPAMPA. Pró-Reitoria de Graduação. Relatório Anual de Atividades do PIBID - 2015. Disponível em: <https://sites.unipampa.edu.br/PIBID/relatoriosde-atividades-PIBIDunipampa/> Acesso em: 20 out. 2019.

UNIPAMPA. Pró-Reitoria de Graduação. Relatório Anual de Atividades do PIBID - 2016. Disponível em: <https://sites.unipampa.edu.br/PIBID/relatoriosde-atividades-PIBIDunipampa/> Acesso em: 20 out. 2019.

UNIPAMPA. Pró-Reitoria de Graduação. Relatório Anual de Atividades do PIBID - 2017. Disponível em: <https://sites.unipampa.edu.br/PIBID/relatoriosde-atividades-PIBIDunipampa/> Acesso em: 20 out. 2019.

\section{Sobre os autores}

\section{Evandro Ricardo Guindani}

evandroricardo1@gmail.com

Professor Adjunto do Campus São Borja, da Universidade Federal do Pampa, docente no Curso de Ciências Humanas - Licenciatura. Coordenador de Área do Núcleo Ciências Humanas do PIBID/UNIPAMPA 2014-2017 e Professor Colaborador no período de 2018 a 2020.

\section{Ângela Maria Hartmann}

angelahartmann@unipampa.edu.br

Professora Associada do Campus Caçapava do Sul, da Universidade Federal do Pampa, docente no Curso de Ciências Exatas - Licenciatura, na Especialização em Educação Científica e Tecnológica, na Especialização em Gestão e Educação Ambiental e no Mestrado Profissional em Ensino de Ciências. Coordenadora Institucional do PIBID/UNIPAMPA 2019-2022.

\section{Yáscara Michele Neves Koga}

yascaraguindani@unipampa.edu.br

Professora Adjunta do Campus São Borja, da Universidade Federal do Pampa, docente no Curso de Ciências Humanas - Licenciatura. Coordenadora de Área do Núcleo Ciências Humanas do PIBID/UNIPAMPA 2019-2020. Professora Colaboradora no período de 2016 a 2018. 